
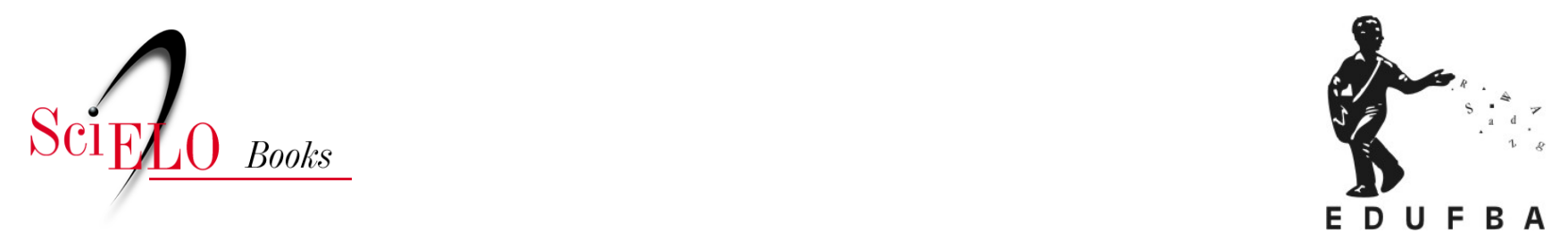

\title{
Capítulo 4 - Corpo, identidade, cultura e risco reflexões sobre o excesso de peso em contexto urbano
}

\author{
Tatiana Coura Oliveira \\ Dina Czeresnia \\ Eliane Portes Vargas
}

\section{SciELO Books / SciELO Livros / SciELO Libros}

OLIVEIRA, T.C.., CZERESNIA, D., and VARGAS, E.P. Corpo, identidade, cultura e risco: reflexões sobre o excesso de peso em contexto urbano. In: BOSI, M.L.M., PRADO, S.D., And AMPARO-SANTOS, A., comps. Cidade, corpo e alimentação: aproximações interdisciplinares [online]. Salvador: EDUFBA, 2019, pp. 119-151. ISBN: 978-65-5630-010-8. https://doi.org/10.7476/9786556300108.0007.

All the contents of this work, except where otherwise noted, is licensed under a Creative Commons Attribution 4.0 International license.

Todo o conteúdo deste trabalho, exceto quando houver ressalva, é publicado sob a licença Creative Commons Atribição 4.0. 


\section{Corpo, identidade, cultura e risco reflexões sobre o excesso de peso em contexto urbano'}

TATIANA COURA OLIVEIRA, DINA CZERESNIA E ELIANE PORTES VARGAS

\section{INTRODUÇÃO}

Este trabalho problematiza a relação entre excesso de peso e construção da identidade em mulheres de camadas populares em um contexto urbano específico, a cidade do Rio de Janeiro. No entanto, o material

1 As reflexões aqui apresentadas consistem em desdobramento da pesquisa "Concepções e práticas alimentares e corporais de mulheres com excesso de peso", apresentada em 2016 ao Programa de Pós-Graduação em Epidemiologia em Saúde Pública da Escola Nacional de Saúde Pública Sergio Arouca - Fundação Oswaldo Cruz, portanto apoiam-se nos mesmos referenciais teórico-metodológicos acrescidos de outros. Alguns resultados da pesquisa já foram discutidos no artigo "Concepções sobre práticas alimentares em mulheres de camadas populares no Rio de Janeiro, RJ, Brasil: transformações e ressignificações”. Entretanto, a realização do trabalho de campo realizado em um bairro de uma cidade do Rio de Janeiro produziu reflexões adicionais sobre o viver na cidade que puderam ser aqui exploradas adicionalmente. 
aqui analisado apresenta características observadas também em outros contextos urbanos. Parte-se de uma compreensão de cidade, para além de seu delineamento geográfico, como um lugar-espaço de realização de práticas de controle sobre o corpo, culturalmente conduzidas pela lógica de risco. As conexões entre obesidade e risco, e também o estigma, relacionam-se ao caráter individualista das prescrições que regem os discursos de prevenção e promoção da saúde alimentar. (CZERESNIA, 2004; OLIVEIRA; CZERESNIA; VARGAS, 2017) A disseminação das informações sobre o risco encontra-se amplificada nos grandes centros urbanos por meio de recursos tecnológicos que acirram contradições e retroalimentam o mercado de consumo e a oferta de serviços por expertises que as conformam. Nesta direção, o hiperpreventivismo, enquanto estratégia de controle dos possíveis males que podem acometer esse corpo-cidade, também intervém na produção da subjetividade. O excesso de peso se configura como uma pandemia contemporânea que atravessa as sociedades em termos globais, apesar de serem observadas características diferenciadas considerando-se idade, gênero, bem como relacionadas às condições de vida entre aqueles em situação de vulnerabilidade social. (SWINBURN et al., 2011)

Ressalta-se que as condições que conduzem ao crescimento nos índices epidemiológicos de sobrepeso e obesidade se realizam em meio a uma crescente valorização do corpo magro como padrão estético, num contexto evidente de lipofobia social. (FISCHLER, 1995) A realidade epidemiológica do excesso de peso se contrapõe à ascensão de um ideal estético oposto, revelando uma incongruência e uma dificuldade de adequação social a esse padrão normativo. $O$ termo "normal" designa duplamente o que é ideal, o que é como deve ser; e o que ocorre na maior parte dos casos, ou que constitui a média de uma condição mensurável. (CANGUILHÉM, 2012) O acirramento dessa contradição entre as duas acepções do termo "normal" incita o agravamento de tensões: a obesidade promove insatisfação corporal e processos de estigmatização em diferentes níveis. (PARKER, 2012) Depressão, ansiedade, baixa autoestima, insatisfação corporal e pequena procura por cuidados de saúde são 
citados como efeitos adversos à estigmatização da obesidade. (PUHL; HEUER, 2010)

Historicamente, a intensificação do valor estético atribuído à magreza se dá a partir da segunda metade do século XX, produzindo sentidos sociais desqualificadores para a gordura corporal: o corpo contemporâneo se transformou progressivamente em referencial para a construção das identidades pessoais, nas quais atributos físicos determinam e marcam a definição de um lugar no mundo. Uma série de atributos morais positivos, como fertilidade, força e atratividade, anteriormente associados à gordura corporal foi substituída por imagens negativas. (VARTANIAN; SILVERSTEIN, 2013) Essas transformações não ficaram confinadas a áreas geográficas específicas, mas repercutiram de maneira global. Para Hall (1997), o encurtamento da relação tempo-espaço, favorecido pelas atuais tecnologias de comunicação, propiciou o enredamento da sociedade contemporânea, em complexas redes de significados em detrimento destas se situarem em fusos horários diferenciados ou delimitados territorialmente a partir de certa concepção de cidade.

Ademais, ainda que as cidades se caracterizem por diferentes histórias e estágios de desenvolvimento, bem como distintos modos e estilos de vida, o "viver na cidade" constitui parte e expressão de fenômenos complexos como as relações de identidade, etnicidade, territorialidade, globalização, lugares, fronteiras, situações às margens etc. (AGIER, 2011) Segundo o autor, trata-se de conceber a cidade como processo e observá-la em meio a dinâmicas relacionais configuradas por diferentes saberes, espaços e situações, sendo pertinente analisá-las na construção do conhecimento sobre as cidades e os contextos urbanos. Nessa perspectiva, transformações globais mais amplas da cultura impactam o "local e o cotidiano", ressignificando modos de viver e sentidos atribuídos às experiências locais, de todo modo cultural.

Beleza e aceitação social, como valores positivos do mundo contemporâneo que se ligam diretamente aos hábitos de vida relacionados à alimentação e à aparência corporal, se tornaram dimensões de grande repercussão na subjetividade e na vida cotidiana. (GIDDENS, 1991) 
Tais dimensões atravessam o tempo e o espaço para além daquele geograficamente delimitado. Nestes termos, Hall (1997) aponta a centralidade da cultura e suas dimensões globais como constitutiva em todos os aspectos da vida social na segunda metade do século XX.

Percebe-se claramente nesta passagem as transformações no modo de vida das pessoas comuns - transformações ocorridas nas culturas da vida cotidiana: o declínio do trabalho na indústria e o crescimento dos serviços e outros tipos de ocupação, com seus diversos estilos de vida, motivações, ciclos vitais, ritmos, riscos e recompensas; o aumento dos períodos de folga e o relativo vazio do chamado 'lazer'; o declínio das perspectivas de 'carreira' e dos empregos vitalícios dando lugar ao que tem sido chamado de 'flexibilidade no emprego', mas que, frequentemente, constitui uma questão de desemprego não planejado; as mudanças no tamanho das famílias, nos padrões de diferenças de geração, de responsabilidade e autoridade dos pais; o declínio do casamento numa época de incremento do divórcio, o aumento de famílias uniparentais e a diversificação de arranjos familiares; o envelhecimento da população, com seus dilemas acerca de uma terceira idade mais longa sem a ajuda do cônjuge, sustentada por generosos programas nacionais de seguros, sistemas públicos de saúde e outros sistemas de benefícios estatais; a redução das tradicionais idas à igreja e da autoridade dos padrões morais e sociais tradicionais e das sanções sobre as condutas dos jovens; os conflitos de gerações em consequência da divergência entre jovens e adultos, entre o declínio da ética puritana, de um lado, e o crescimento de uma ética consumista hedonista, de outro. Tais mudanças são relacionadas, de alguma forma, a situações sociais, de classe e geográficas: e não exclusivamente de classe. (HALL, 1997, p. 21-22)

Em se tratando de excesso de peso, podemos pensar, apoiados no autor, nos poderes determinantes de controle reincidente e sobreposto à cultura no que tange às imagens do corpo e de construção da subjetividade que circulam na cena urbana. (HALL, 1997) O modelo cultural predominante de "corpo aceito" socialmente foi legitimado pelo discurso biomédico e potencializado pela associação do excesso de peso a agravos à saúde, produzindo repercussões sobre os sentidos ligados ao corpo, independente de classe ou grupo social, porém com efeitos mais perversos sobre as mulheres. (BREWIS; HRUSCHKA; WUTICH, 2011; DEVAUX; SASSI, 2013) O aumento nos indicadores globais de 
excesso de peso levanta a necessidade de reflexões sobre questões mais amplas que se ligam às práticas alimentares em seu contexto micro e macrossocial, cujas transformações não se restringem à ampliação do acesso à informação nutricional ou orientação prescritiva em saúde. (STUCKLER; NESTLE, 2012)

Pressionados por normas provenientes do discurso médico, por padrões estéticos idealizados e delimitados por condições materiais de existência que moldam o consumo permeado por imposições da indústria de alimentos e da produção agrícola, diferentes grupos socioculturais são universalmente afetados pelo excesso de peso, porém de modos e com consequências muito distintas. Nesse cenário, há um predomínio de abordagens parciais de enfrentamento ao excesso de peso que, no âmbito da saúde, são pautadas na recomendação de práticas alimentares "saudáveis" com forte presença de um discurso que superestima o papel da gestão individual (CASTIEL; MORAES; PAULA, 2016), adicionado de uma proliferação, em diferentes instâncias, de orientações alimentares baseadas em perspectivas contraditórias que semeiam divergências, além de produzirem informações controversas. (RODGERS, 2016) A divulgação do discurso do risco com fins de promoção da saúde se confunde com a de recomendações voltadas predominantemente a um padrão estético.

\section{PERSPECTIVAS TEÓRICO-METODOLÓGICAS, O CAMPO E O UNIVERSO DA PESQUISA}

Mediante a natureza complexa do problema e sua expresssão em contextos específicos, esta pesquisa buscou problematizar a relação entre excesso de peso e construção da identidade em mulheres de camadas populares em um contexto urbano. A designação "camadas populares" ou "classes populares" assumida na pesquisa apoia-se na vertente de tradição antropológica que designa determinados seguimentos sociais em contexto urbano no Brasil como "classes trabalhadoras". (DUARTE, 1988) Não corresponde, portanto, a uma definição do grupo do estudo exclusivamente por critérios de classificação de renda, mas a um gradiente mais 
amplo de características que comporta as dimensões simbólicas e culturais delimitadoras de determinados grupos sociais, sobretudo aqueles que são parte de sociedades complexas, como a sociedade contemporânea, constituídas de amplos processos, como o da globalização.

A estratégia adotada considerou a importância de se incluir o ponto de vista das mulheres entrevistadas, ou seja, de valorizar a perspectiva de quem vive a experiência que está sendo apresentada na interação com o pesquisador. Esse recurso foi fundamental para relativizar a especificidade do olhar de profissional nutricionista da pesquisadora principal, considerando que a produção do dado não está isolada do sujeito que realiza a pesquisa. (PEIRANO, 2014) Esses sentidos foram interpretados em articulação com aspectos macrossociais que contextualizam a questão em relação às dimensões culturais como estigma e risco a partir dos discursos sociais produzidos sobre a obesidade.

O trabalho foi desenvolvido a partir de uma perspectiva etnográfica, entendendo o método como uma forma de nos aproximarmos da realidade das pessoas, valorizando a compreensão do caráter multidimensional do fenômeno em sua manifestação social e cultural, bem como a captação dos sentidos da experiência vivida e singularidade do indivíduo. (PEIRANO, 1995) Assim como a aproximação do pesquisador em relação ao fenômeno que se pretende compreender, tal processo só é possível a partir da compreensão de que a teoria é indissociável da prática. (VICTORA; KNAUTH; HASSEN, 2000)

Conformada pela atenção constante sobre o que e como ocorre, considerando que a observação empírica afeta o campo e a vida social, percebe-se a impossibilidade de se isolar a produção do conhecimento do sujeito que a produziu. O campo, portanto, ofereceu informações que se transformaram após processo reflexivo, sendo precedido por uma etapa de reconhecimento do território e das diferentes condições de vida e acesso locais. (DAMATTA, 1978)

Partimos da compreensão de que a saúde e seus sentidos são produzidos nos espaços da vida nos quais as pessoas estabelecem conexões. $\mathrm{O}$ indivíduo, a formação do seu corpo e da própria imagem corporal se 
realizam mediante trocas desde as mais básicas e cotidianas, simultaneamente físicas, orgânicas, simbólicas, culturais. (CZERESNIA; MACIEL; MALAGÓN, 2013) Cientes da indissociabilidade entre indivíduo e ambiente, optamos por apresentar características do universo do estudo e do campo da pesquisa, denominado no contexto da saúde como território de Manguinhos, como parte da produção de seus resultados. Nosso intuito é contribuir para uma compreensão ampliada dos elementos em jogo no controle do peso e práticas alimentares no campo da saúde e, em especial, no campo da alimentação e nutrição, refletindo em como esses aspectos podem contribuir na produção de iniquidades sociais.

Manguinhos compreende um conjunto de comunidades com especificidades internas singulares, cujas origens, trajetórias e processos de construções sociais foram configurados historicamente em estreita relação com determinantes políticos, econômicos e sociais. (FERNANDES; COSTA, 2013) Localizado geograficamente entre a Avenida Brasil, a Linha Amarela, a Avenida dos Democráticos e a Avenida Dom Elder Câmara, antiga Avenida Suburbana, Manguinhos é dividida internamente em: Parque Carlos Chagas (PCC), Parque João Goulart (PJG), Parque Oswaldo Cruz/Morro do Amorim (POC), Comunidade Samora Machel (CSM), Comunidade Nelson Mandela (CNM), Comunidade Mandela de Pedra (CMP), Comunidade Agrícola de Higienópolis (CAH); Conjunto Habitacional Provisório 2 (CHP2), Vila São Pedro (VSP), Vila Turismo (VT), Vila União (VU), Embratel, Comunidade Vitória de Manguinhos (CVM) e Condomínio Departamento de Suprimentos do Exército (DSUP). Manguinhos está entre as cinco piores situações, considerando o Índice de Desenvolvimento Humano (IDH) ${ }^{2}$ do Rio de Janeiro, junto com Guaratiba, Rocinha, Jacarezinho, Maré e Complexo do Alemão.

$2 \mathrm{O}$ IDH avalia as condições de vida de uma população a partir de três dimensões principais: educação, renda e saúde. O IDH educação incorpora ainda dois indicadores: a taxa de alfabetização e a taxa bruta de frequência à escola. $\mathrm{O}$ IDH renda inclui apenas o indicador da renda per capita. O IDH saúde inclui a esperança de vida ao nascer e expressa o patamar de desenvolvimento humano de diferentes regiões e países. 
A região é marcada pela precariedade habitacional, insuficiência de serviços públicos e graves problemas ambientais que influenciam de forma importante a qualidade de vida de seus moradores e compõem o mosaico de desigualdades sociais que expressa a cidade do Rio de Janeiro. (FERNANDES; COSTA, 2013) Em 2007, as Secretarias Municipais de Saúde e Educação contabilizam uma população de 45 mil habitantes no território de Manguinhos, população que correspondia a 0,74\% de um total de 6.093.47 de habitantes da cidade do Rio de Janeiro. (CUKIERMAN; TEIXEIRA, 2008)

O Centro de Saúde Escola Germano Sinval Faria (CSEGSF) foi escolhido como local principal de coleta de dados por duas razões: (1) este Centro se constitui em uma referência de atendimento à saúde; (2) razões de segurança relacionadas ao avanço da violência nesse território, mediante o agravamento da crise econômica e sociopolítica no país. A entrada no campo foi facilitada pela equipe de Nutrição do Centro de Saúde e responsáveis administrativos do serviço. ${ }^{3}$ As vivências sociais em territórios tais quais Manguinhos são atravessadas pelas contradições inscritas no próprio espaço urbano. Elas produzem subjetividades originárias de uma sociabilidade ambígua nos indivíduos, pois se o território é, de um lado, fonte de toda sorte de violência e justamente por isso "prospera" na exata medida da falta dos direitos civis, por outro, se revela ali uma dimensão que o protege das forças do mercado, ao mesmo tempo em que o priva da "cidade", oferecendo-lhe alguma forma de acesso à comunidade. (BURGOS, 2002)

Desenvolvido entre os meses de setembro e novembro de 2015, o trabalho de campo considerou as seguintes etapas: (1) realização de observação dos atendimentos ambulatoriais de nutrição, dos encontros de um grupo de apoio multidisciplinar a usuários do serviço que apresentavam excesso de peso e de visitas domiciliares realizadas por uma agente de saúde no território; e (2) entrevistas semiestruturadas com as

3 Pesquisa aprovada pelo Comitê de Ética em Pesquisa da Escola Nacional de Saúde Pública Sergio Arouca (ENSP)/Fundação Oswaldo Cruz (Fiocruz), sob o parecer de número 1.138.011. 
usuárias do serviço de saúde. A observação e as entrevistas foram realizadas mediante utilização de roteiros previamente elaborados, sendo o último composto por dois blocos temáticos: práticas alimentares $\mathrm{e}$ corpo/alimentação. No primeiro, foi abordada a rotina de alimentação das informantes, na qual foram produzidas informações acerca das práticas, costumes e critérios eleitos no âmbito da escolha alimentar. No segundo, foram tratadas questões ligadas ao corpo e alimentação, considerando as perspectivas biomédica, cultural e de gênero.

Buscou-se, desse modo, estabelecer conexões entre as unidades de sentido identificadas e a literatura. $O$ início da conversa sempre partia de uma narrativa ligada à vida da informante, relacionada às vivências pessoais. A pergunta “me conta, quem é você? o que faz?" dava início ao processo, que era direcionado de acordo com as questões que compunham o roteiro. (FRASER; GONDIM, 2004) Após a etapa de observação, os convites para participação no estudo foram dirigidos às usuárias do serviço que apresentavam excesso de peso, sendo essa identificação realizada visualmente em um primeiro momento. Tendo em vista a natureza qualitativa do estudo, tentou-se evitar constrangimentos ou barreiras que pudessem dificultar a abertura de um canal dialógico adequado. Neste sentido, a aferição do peso e da altura para o cálculo do Índice de Massa Corporal $\left(\mathrm{IMC}=\mathrm{kg} / \mathrm{m}^{2}\right)$ era realizada ao final da entrevista. Considerou-se, na avaliação, o sistema de classificação sugerido pela WHO (1995) que estratifica o excesso de peso em "obesidade" para aquele indivíduo que possuir um IMC maior ou igual a $30 \mathrm{~kg} / \mathrm{m}^{2}$ e em "sobrepeso" para aqueles com IMC entre 25 e $29,9 \mathrm{~kg} / \mathrm{m}^{2}$.

Ao todo, foram entrevistadas 21 mulheres, cujas características principais estão descritas a posteriori para uma melhor contextualização sociocultural do grupo. Todas são usuárias do CSEGSF. Em relação ao diagnóstico nutricional, dentre as 21 informantes, 18 possuíam obesidade em seus diferentes níveis: grau I ( $\mathrm{n}=8)$, grau II $(\mathrm{n}=5)$ e grau III $(n=5)$, estando as demais $(n=3)$ em situação de sobrepeso. Com idades compreendidas entre 23 e 64 anos, parte das informantes era proveniente da zona rural nordestina $(\mathrm{n}=5)$ ou zona rural do Espírito Santo $(\mathrm{n}=1)$, ou ainda do interior do Rio de Janeiro $(\mathrm{n}=1)$, cujas histórias 
singulares de migração aconteceram como tentativas de melhores condições de vida; as demais $(\mathrm{n}=14)$ haviam nascido na própria comunidade ou periferia urbana do Rio de Janeiro, sendo possível encontrar alguns relatos de migração dos pais $(\mathrm{n}=2)$ ou avós paternos ou maternos $(n=3)$ vindos, em sua maioria, do interior de outros estados brasileiros.

Quanto à escolaridade, apesar de estarem majoritariamente inseridas em ocupações com menor exigência escolar, há um predomínio de mulheres com ensino médio completo $(\mathrm{n}=10)$, seguido de ensino fundamental $(n=7)$ e ensino superior $(n=3)$, completo ou incompleto. Apenas uma das informantes relatou nunca ter frequentado uma escola, apesar de não ser analfabeta. Nos arranjos familiares, houve um predomínio do tipo mulher e cônjuge com filhos, sendo mais frequente a união consensual com início na juventude. Havia ainda duas entrevistadas solteiras com filhos, uma viúva e uma com o marido no cárcere.

Em relação à ocupação, 13 entrevistadas trabalhavam no setor formal em atividades como limpeza e serviços gerais $(n=6)$, serviços de saúde $(n=4)$, cozinheira $(n=1)$, auxiliar de escritório $(n=1)$, técnica em enfermagem $(n=1)$. Entre aquelas ligadas ao setor informal de trabalho, três exerciam serviços de limpeza em domicílios, uma era manicure e uma catadora de material reciclável. Havia duas pensionistas do Instituto Nacional do Seguro Social (INSS) - uma por tempo de contribuição; outra por viuvez - e uma desempregada. O salário dessas mulheres era a única fonte de renda para uma considerável parte das famílias ( $n=9$ ), sendo também importante na complementação financeira das demais $(n=12)$.

Atividades de seleção e de preparo dos alimentos eram de responsabilidade das entrevistadas, sendo realizadas nos intervalos entre uma ou outra atividade doméstica. Na maioria dos casos, as compras de gêneros alimentícios eram feitas em hipermercados localizados em bairros adjacentes ao território, ficando itens perecíveis, como hortifrutigranjeiros ou produtos cárneos, para serem adquiridos em Manguinhos, quando possível. 


\section{AS ENTREVISTADAS, UM POUCO ALÉM DO IMC}

E1 [Nordestina de Pernambuco, 45 anos, IMC 37,8 kg/m²]

E1 migra aos 14 anos para o Rio de Janeiro com uma promessa de emprego. Ao chegar, descobre que havia sido trazida para prostituição. Foge pouco tempo depois do local onde estava e passa a trabalhar como empregada doméstica. Casou-se posteriormente, mas a relação mantinha um caráter violento: "Escrava de marido: lavando, passando, cozinhando, arrumando e apanhando... Lavando, passando, cozinhando, arrumando $e$ apanhando. Porque ele me batia muito". Sabe ler e escrever, mas não foi alfabetizada institucionalmente. Vive atualmente com um segundo companheiro em um apartamento na comunidade do Mandela com o auxílio do Programa Aluguel Social, do Rio de Janeiro. Trabalha como cozinheira em um restaurante comercial no centro do Rio. E1 é hipertensa.

E2 [Nordestina da Paraíba, 47 anos, IMC $55,55 \mathrm{~kg} / \mathrm{m}^{2}$ ]

Filha de um agricultor e uma professora, trabalhava de dia em sua cidade e fazia graduação em Pedagogia à noite em Campina Grande. Casou-se aos 24 anos com um rapaz que, apesar de paraibano, residia e trabalhava no Rio de Janeiro: “Quando eu vim pra cá, a gente foi morar na Ilha. Lá na praia da rosa [...] nunca tinha visto favela na minha vida. Mas aí o tempo foi passando e eu fui me acostumando". Separou-se do marido por causa do seu alcoolismo. Hoje, trabalha como auxiliar em um escritório de contabilidade em Caxias e vive com os dois filhos em Manguinhos. É hipertensa e diabética.

E3 [Nordestina do Rio Grande do Norte, 43 anos, IMC 37,66 kg/m²]

Chegou ao Rio de Janeiro com 25 anos para perpetuar uma relação amorosa extraconjugal que havia começado em sua cidade natal. Grávida, ficou hospedada com um irmão na comunidade do Jacaré. Sobre sua vida no Rio Grande do Norte: “Assim, eu... Meu marido [o primeiro] tinha mais condições que meu pai. E ele bancava... Eu tinha vida de 
princesa em casa [...]. Depois que eu vim pra cá pro Rio éque a coisa pegou! Trabalhar, tomar conta de casa... De marido... Eu falava assim: eu quero voltar pro Norte!". Atualmente, mora na comunidade do Mandela em casa própria, com o segundo marido e dois filhos desta relação. Trabalha como diarista em Bonsucesso. Já fez consulta com uma nutricionista com vistas à perda de peso.

\section{E4 [Curicia/RJ, 56 anos, IMC 30,82 kg/m²]}

Passou a primeira infância com sua madrinha no estado do Rio de Janeiro porque a mãe realizava tratamento para tuberculose em Minas Gerais. É separada, possui dois filhos de dois relacionamentos anteriores. Trabalha desde os 14 anos e há 21 anos presta serviço na área de limpeza nas dependências da Fiocruz. Reside na comunidade do Amorim, em imóvel que é herança paterna. Já fez consulta com uma nutricionista, mas não faz nenhum acompanhamento para perda de peso no momento.

\section{E5 [Rio de Janeiro/RJ, 28 anos, IMC 25,1 kg/m²]}

Trabalha como auxiliar de serviços gerais, residindo atualmente no DSUP com os três filhos. Seu marido está no cárcere. Informante mais fechada, falou pouco durante a entrevista, sempre com respostas rápidas e curtas. E5 nunca consultou uma nutricionista.

\section{E6 [Capixaba/ES, 64 anos, IMC 29,77 kg/m²]}

Migrou com a família para o Rio aos 13 anos, é a mais velha entre as irmãs de um total de dez irmãos. Vindos do Espírito Santo, fugiram de uma situação de miséria e fome. Sempre atuou no setor informal, a princípio como empregada doméstica e, mais recentemente, como diarista. Chama a atenção sua preocupação com o peso. Já fez consulta de nutrição.

\section{E7 [Duque de Caxias/RJ, 30 anos, IMC 30,13 kg/m²]}

É técnica em Enfermagem e está cursando graduação na área. E7 relata uma infância difícil: "Minha infância foi um pouco triste. Um pouco triste porque [...] eu passei muita necessidade. [...] Eu já fiquei na porta de 
padaria pedindo pão". Acabou de pedir demissão em um hipermercado - trabalhava como caixa - para assumir um emprego como técnica em hemodiálise numa clínica especializada. Possui carro e casa própria no Amorim. Nunca fez consulta com nutricionista, mas acompanha dois dos seus três filhos por apresentarem hiperglicemia e hipercolesterolemia.

E8 [Carioca, Rio de Janeiro, 36 anos, IMC $25,91 \mathrm{~kg} / \mathrm{m}^{2}$ ]

Relata ter tido uma infância difícil, inclusive com falta de alimentos em casa, situação que piorou após a morte do pai. Retomou os estudos após o nascimento da segunda filha - na época da entrevista, com três anos - e sonha em fazer Psicologia. E8 trabalha como agente comunitária no CSEGSF, mora com o companheiro e com a filha mais nova na comunidade agrícola de Higienópolis.

E9 [Carioca, Rio de Janeiro, 51 anos, IMC 35,58 kg/m²]

Trabalha em empresa terceirizada na Fiocruz prestando serviço de limpeza. Tem o ensino médio completo, é casada há 28 anos e tem dois filhos. Teve uma infância tranquila, segundo conta. Nunca fez consulta nutricional, entretanto já procurou endocrinologista para perda de peso.

E10 [Carioca, Rio de Janeiro, 29 anos, IMC $30,89 \mathrm{~kg} / \mathrm{m}^{2}$ ]

É casada, mas não tem filhos. Apesar de estar desempregada, possui curso técnico em Administração. Já consultou nutricionista e endocrinologista para perda de peso, mas, em seu relato, disse preferir atendimento do médico ao nutricional. Segundo relato, "era bem magrinha... que sempre vivia muito doente e depois foi me dando vitamina, ficava muito internada. Depois fui engordando... [...]. Eu era bastante forte mesmo, mais forte que eu sou hoje".

E11 [Nordestina da Paraíba, 33 anos, IMC 33,33 kg/m²]

Veio para o Rio procurando condições melhores de vida. Ficou hospedada com um tio em Campo Grande/RJ, mas logo foi trabalhar como doméstica, residindo no local de trabalho. Vive em Manguinhos 
desde que trouxe a mãe e a irmã da Paraíba. É casada e tem um filho de 12 anos. Possui ensino médio completo, mas trabalha como faxineira. Já consultou endocrinologista para perda de peso. Apesar de nunca ter ido a um nutricionista, acompanha seu filho, que apresenta excesso de peso, hipercolesterolemia e hiperglicemia nos atendimentos de nutrição.

E12 [Carioca, nascida e criada na Favela do João/RJ, 31 anos, IMC $\left.32,20 \mathrm{~kg} / \mathrm{m}^{2}\right]$

Mora na CMP em uma situação de extrema vulnerabilidade social. Sabe ler, escrever e gosta de frequentar a biblioteca Parque de Manguinhos. Saiu de casa grávida do primeiro filho e foi morar com o companheiro. O segundo filho do casal é criado pela avó materna, que mora em Sepetiba/RJ. E12 é catadora de material reciclável, mas não considera isso um trabalho. Seu marido é responsável pelo transporte e venda do material coletado. Está tentando perder peso e já fez atendimento nutricional.

\section{E13 [Nordestina da Bahia, 54 anos, IMC $66,83 \mathrm{~kg} / \mathrm{m}^{2}$ ]}

Migrou para o Rio de Janeiro aos 17 anos na busca de uma vida melhor. Instalou-se com um tio na comunidade do Jacaré e começou a trabalhar em uma indústria de produtos químicos na própria região. E13 é casada e tem um único filho. Apresenta obesidade severa há muitos anos e desde sempre luta contra a situação. Sua narrativa é marcada por momentos de choro e frustação, mas também pela alegria de estar viva.

\section{E14 [Carioca, Rio de Janeiro, 42 anos, IMC 40,83 kg/m²]}

Possui distrofia progressiva, uma má formação genética que limita a locomoção. Passou parte da infância com a avó e, após o falecimento dela, ficou com tios em Duque de Caxias, vindo para Manguinhos logo depois. Casou aos 19 anos e, após o nascimento de sua segunda filha, percebeu a necessidade de voltar a estudar. E14 se divorciou aos 38 anos e vive na CSM com três filhas e uma neta. Tem o ensino médio completo 
e trabalha com agente no projeto Teias-Manguinhos. Nunca procurou ajuda para perder peso.

E15 [Carioca, nascida e criada em Manguinhos/RJ, 29 anos, IMC $\left.57,7 \mathrm{~kg} / \mathrm{m}^{2}\right]$

É filha de pai piauiense e mãe paraibana, casada e mãe de um filho. E15 possui ensino médio completo e é manicure em um salão de beleza em Manguinhos. Possui uma relação difícil com a mãe, que, em seu relato, apresentava-se desde a infância extremamente controladora da sua alimentação. Iniciou ganho de peso entre 15 e 16 anos. Já procurou clínico geral e nutricionistas para perder peso, já foi atendida também no Centro de Referência de Obesidade (CRO) na Penha e tem novo encaminhamento para o serviço.

E16 [Carioca, nasceu e cresceu em São Cristóvão/RJ, 35 anos, IMC $\left.35,53 \mathrm{~kg} / \mathrm{m}^{2}\right]$

E16 mora atualmente em Manguinhos com dois filhos. Está desempregada há sete meses e vive da pensão de morte do pai de seus filhos. Considera ter tido uma boa infância. Fez sua primeira consulta de nutrição na semana em que fizemos a entrevista.

E17 [Carioca, nascida e criada no Amorim/RJ, 28 anos, IMC 30 kg/ $\left.\mathrm{m}^{2}\right]$

Casada, sem filhos, trabalha como agente comunitária no centro de saúde, apesar da formação como técnica em Enfermagem e mais recentemente como nutricionista, graduação realizada em uma instituição de ensino superior privada instalada em Bonsucesso. Morou por um ano em Caxias e há duas semanas retornou ao Amorim. Muito tranquila e comunicativa, não expressou a presença de limitações financeiras severas na infância, mas relatou história paterna de alcoolismo. Desde a adolescência, enfrenta problemas com o peso. 
E18 [Carioca, nascida e criada no Amorim/RJ, 48 anos, IMC 41,64 $\left.\mathrm{kg} / \mathrm{m}^{2}\right]$

Filha de pai português e mãe nordestina, é auxiliar de serviços gerais na Fiocruz. É separada, cuida de uma sobrinha de sete anos e tem uma filha de 23 anos, que mora na Penha. Nunca procurou nutricionista ou endocrinologista para perder peso.

\section{E19 [Carioca/RJ, 33 anos, IMC 33,78 kg/m²]}

É casada há quase 20 anos e tem dois filhos: um rapaz de 17 e uma menina de 10 anos. Suas memórias indicam uma infância difícil, pois a mãe era a única responsável por oito filhos e três sobrinhos abandonados pela irmã. E19 trabalha como auxiliar de serviços gerais e possui casa própria na comunidade de Manguinhos. Está tentando perder peso, tendo iniciado atividade física em academia particular no mês anterior à entrevista. E19 nunca fez uma consulta de nutrição.

\section{E20 [Carioca/RJ, 23 anos, IMC 35,33 kg/m²]}

Possui o ensino médio completo, mora de aluguel na comunidade de Manguinhos com os filhos, a mãe, um irmão e dois sobrinhos. Um dos filhos participa do programa de desnutridos do CSEGSF, de onde recebe uma cesta básica/mês. Apesar de acompanhar o filho no atendimento do programa, nunca fez uma consulta nutricional.

\section{E21 [Carioca/RJ, 57 anos, IMC 28,5 kg/m²]}

Solteira, E21 mora com a filha única em casa própria na comunidade de VU. Apresenta um histórico de inúmeras interrupções na vida escolar, conseguindo se formar em magistério no começo da década de 1980. Nunca conseguiu se colocar na profissão, tendo atuando como catadora de material reciclável e como empregada doméstica para se sustentar. Formou-se posteriormente como técnica em Enfermagem, profissão que exerce no CSEGSF. Demonstra grande preocupação com a alimentação e com o corpo. 


\section{TEMPO, MEMÓRIA, SUBJETIVIDADE E COMER NA CIDADE}

Em relação à dieta, é difícil cuidar... É difícil cuidar, porque eu não tenho muito tempo pra fazer a dieta, também não tenho [faz um gesto discreto com a mão esquerda, esfregando o indicador e o polegar], porque dieta é caro. É caro, num é barato. (E2, 47 anos, IMC 55,55 kg/m²)

O relativamente recente e acelerado processo de urbanização brasileira está articulado a um conjunto de mudanças socioeconômicas e políticas que precisam ser consideradas na compreensão dos processos ligados às transformações, permanências e incorporações das práticas alimentares. O lócus privilegiado de atividade econômica nas cidades brasileiras fez com que estas se tornassem difusoras de novos padrões sociais, que incluem, dentre outros aspectos, o consumo alimentar. (BRITO, 2006)

Ocorrida a partir da segunda metade do século xx, a urbanização obteve seu auge entre os anos de 1950 e 1970, fomentando também o processo migratório. Esse movimento precisa ser levado em consideração para se compreender como a reestruturação das relações dos territórios com a cidade impactou não somente no padrão de sociabilidade anteriormente existente, fomentando um processo de integração social pautado em impessoalidade e formação de frágeis identidades coletivas territoriais, mas também em novas formas de consumo. (BURGOS, 2005)

Conformada pela forma hegemônica contemporânea de produção e distribuição de alimentos, a migração campo-cidade favorece um processo de transição no padrão alimentar dos indivíduos. De modo geral, podem ser considerados três desdobramentos possíveis no processo de transição do padrão alimentar: o primeiro relacionado à presença de uma dicotomia na qual novas possibilidades são adotadas, ainda que as antigas sejam adaptadas; o segundo apresenta maior indefinição e menor autonomia com significativo risco de desequilíbrio alimentar; enquanto o terceiro é caracterizado por uma desestruturação dos elementos de origem sem que se reconstrua organizadamente um novo padrão alimentar, possibilidade esta ligada a uma desvinculação sociocultural e à vulnerabilidade econômica. (CALVO, 1982) 
Embora aparentemente simples, as escolhas alimentares são comportamentos complexos e determinados por muitos fatores e interações. Nesse sentido, para uma melhor compreensão dos achados da investigação, os resultados foram articulados a partir das transformações nas práticas alimentares das informantes decorrentes de um processo de migração e consolidação da vida na periferia urbana, passando pela experimentação corporal do excesso de peso e contradições dos sentidos atribuídos ao binômio saúde/estética; considerando-se o predomínio, no campo da saúde, de um discurso que culpa o indivíduo pelo próprio excesso de peso. (CASTIEL; MORAES; PAULA, 2016)

As percepções das informantes sobre as práticas alimentares, tanto as atuais quanto as da infância, expressam sentidos socialmente atribuídos e localizados na memória. Nas narrativas das entrevistadas, é possível, por exemplo, perceber o quanto as memórias relacionadas à alimentação no passado são experiências presentes na elaboração de uma nova prática alimentar. Marcadas por crenças, tabus, cerimônias e distinções, as práticas e sistemas alimentares revelam repetidamente a cultura em que cada um está inserido. (MACIEL, 2001) As atitudes relacionadas à comida são normalmente apreendidas precocemente e conferem ao comportamento um poder sentimental duradouro.

Apesar da adaptação humana a uma variedade de possibilidades alimentares, a seleção do que comer está para além de questões básicas de subsistência e de manutenção da vida. Ela é baseada em escolhas que perpassam tanto questões culturais, como tradições e tabus, quanto por situações geopolíticas, como urbanização e distanciamento da produção agrícola, bem como econômicas, sendo estas socialmente compartilhadas. Nesse sentido, considerando as variações do tempo e da memória das entrevistadas, duas formas de consumo alimentar emergem nas narrativas: uma ligada ao manejo da terra presente entre as migrantes e outra marcadamente agroindustrial, articulada aos modos de vida na periferia urbana. Cabe considerar que tais modelos são aqui considerados de modo não excludentes, sendo apresentados separadamente apenas para efeito de análise. As memórias que, independentemente da localização geográfica, apontavam escassez 
alimentar, pobreza e miséria ligavam-se simbolicamente a uma determinada forma de comer como apontam os depoimentos abaixo:

A gente comia era inhame de porco... Era banana verde. [...] A gente cozinhava pros bichos e tirava para nós... (E6, 64 anos, IMC $29,77 \mathrm{~kg} / \mathrm{m}^{2}$, migrante da zona rural)

Meu tio trouxe estas coisas da xepa [...] Aí meu primo fez esta sopa de entulho pra gente comer até que minha mãe voltasse. (E8, 36 anos, IMC 25,91 kg/m², nascida na zona urbana)

Castro (2005) chama os alimentos resistentes à seca que não fazem parte da refeição cotidiana de sertanejos, mas que são decisivos para a manutenção da vida em momentos de extrema vulnerabilidade social de "iguaria bárbara". Comer "inhame de porco" ou "sopa de entulho" era uma estratégia de sobrevivência utilizada em momentos críticos, cujo peso simbólico ainda está presente na memória das entrevistadas. Para DaMatta (1986), alimento é tudo aquilo que supre as necessidades de nutrientes e assim corrobora para a manutenção biológica da vida, mas para ser comida é preciso estar atrelado a determinadas representações sociais e culturais. Feijão, por exemplo, é comida; sendo importante marcador da identidade alimentar das entrevistadas. Apesar de os relatos evidenciarem em grande medida uma condição de não satisfação das necessidades básicas, a ausência do feijão no prato era expressão da própria fome. O termo "mistura" também aparece nas narrativas e remete a um grupo de preparações que complementavam a refeição. Segundo Zaluar (1994), "mistura" engloba preparações a base de ovos, carnes e/ou vegetais.

Os aspectos e códigos que determinam um valor simbólico para o "comer" também abrem espaço para a compreensão de como ocorre a ressignificação de antigas práticas frente às novas demandas da vida em um ambiente de periferia marcado por desigualdade, vulnerabilidade e insegurança alimentar. Esse processo pode ser explicado a partir da perspectiva de habitus definida por Bourdieu (1983, p. 65) como "um sistema de disposições duráveis e transponíveis que, integrando todas as experiências passadas, funciona a cada momento como uma matriz de percepções, 
de apreciações e de ações”. A noção de habitus pode favorecer uma reflexão sobre como condicionamentos sociais exteriores ou mesmo a própria subjetividade dos sujeitos, coexistem numa intensa relação de interdependência, expressando o diálogo e a troca constante e recíproca entre as distintas instâncias socializadoras. (BOURDIEU, 1983) Nessa direção, o conceito fornece o caminho para a compreensão de como uma matriz cultural é permeável a transformações advindas, por exemplo, do modo de vida urbano no qual condutas sociais delineiam-se por conformações mais individualistas e articuladas a um ritmo de vida marcado pela escassez de tempo. (DIEZ GARCIA, 2003) No presente, chama a atenção o quanto os produtos ultraprocessados foram incorporados às práticas alimentares das entrevistadas. Antes vistos como supérfluos (ZALUAR, 1994), são agora considerados básicos na alimentação.

O tipo de acesso, os constrangimentos financeiros e as contradições ligadas ao consumo de alimentos industrializados expressam ainda classificações e modos de distinção relacionados ao discurso contemporâneo da alimentação saudável: "Final de semana é o dia do lixo na janta. Da pizza, da lasanha, do industrializado. Lasanha de caixinha, cachorro quente, refrigerante". (E8, 36 anos, IMC 25,91 kg/m²) É importante ressaltar que o "comer" assume posição central no aprendizado social, sendo o comportamento relativo à comida ligado diretamente ao sentido que as pessoas atribuem a si mesmas e à sua própria identidade social.

Nesse sentido, questionamos: qual o sentido atribuído a si mesmo ao se considerar que se come lixo? A presença de sistemas simbólicos ligados ao comer implicam representações e imaginários sociais que envolvem escolhas e classificações nas quais a presença de códigos atua no estabelecimento de relações dos homens entre si e com o ambiente onde estão inseridos. (CANESQUI, 2005) Esse menor valor atribuído por E8 aos ultraprocessados está articulado ao discurso da saúde. Entretanto, conhecê-lo e repeti-lo não são suficientes para uma mudança na prática alimentar; pelo contrário, tais produtos parecem ser apreciados. Um determinado "gosto" pelo industrializado se associa numa perspectiva bourdiesiana a um gosto de classe. (BOURDIEU, 1983) 
Existem particularidades nas possibilidades de acesso e peculiaridades nas formas de consumo entre os diferentes grupos sociais para os quais o mercado se adequa. Grupos sociais economicamente desfavorecidos são mais constrangidos ao consumo de alimentos baratos, práticos e palatáveis que, no entanto, apresentam aditivos químicos, açúcar e sódio em excesso. (CANELLA et al., 2014) Essa realidade se confronta com discurso contemporâneo da saúde, que, ao fomentar uma demanda de consumo de produtos considerados benéficos, exige das informantes constantes ressignificações em relação ao "comer”, as quais oscilam entre o prazer e a culpa. (OLIVEIRA et al., 2017) O depoimento de uma entrevistada é ilustrativo:

Pelo que eu vejo na televisão, olha que você tem que comer comida saudável, salada, aquilo outro... Agora, botô queijo no meio... [suspira]. E eu sei que é ruim. Eu como com pão, com macarrão, com miojo... Vai dizer que isso é bom? Claro que não, eu não sou burra. Que uma comida que fica pronta com 3 minutos, vai dizer que ela é saudável? Ela não é! Não é... De jeito nenhum. [...] E a gente sabe que se alimenta mal, sabe que se alimenta mal, mas... (E1, 45 anos, IMC $37,8 \mathrm{~kg} / \mathrm{m}^{2}$ )

Aspectos da singularidade individual, mesmo em contexto de vulnerabilidade social, assinalam diferenças nas formas de lidar e driblar ou não constrangimentos de natureza econômica, cultural e pessoal que se ligam às práticas alimentares reconhecidas como promotoras do excesso de peso. Uma das narrativas, por exemplo, expressa a preocupação de uma entrevistada com a alimentação:

Se eu vejo que aquilo não tá surtindo efeito, eu mudo pra outra coisa, não fico insistindo. Por exemplo, o que me ajudou a baixar o colesterol foi a farinha de berinjela, entendeu? [...] A quinoa comprei, mas não compro mais, porque acho que não é valido pelo preço, e também o outro faz o mesmo efeito. (E21, 57 anos, IMC $28,5 \mathrm{~kg} / \mathrm{m}^{2}$ )

Embora se caracterizem como grupo de baixa renda, os moradores de Manguinhos representam uma fatia do mercado consumidor para produtos considerados "saudáveis". Se, por um lado, os produtos e 
"fórmulas" veiculados nas mensagens se confrontam a constrangimentos financeiros próprios das camadas populares, por outro, movem-se no imaginário social dessas mesmas mulheres como alternativas possíveis para o alcance de sucesso em relação ao emagrecimento:

Eu tava de férias e aí andando por Bonsucesso, a menina me deu um papelzinho. Aí foi, me convidou pra subir lá no prédio, pra conhecer... Eu disse: 'tô com pressa' e ela 'não, não, mas vamos lá! Só 10 minutinhos!'. Eu fui. Chegando lá, ela já bateu o shake. Me perguntou o sabor que eu queria... Eu queria morango, adorava morango! Ela fez de morango. Bebi. Bebi o chá. Aí ela: 'Ó, vem amanhã pra gente tirar medida' e que num sei o que... Aí mostrou lá aquele tanto de coisa. [...] Em dois meses, eu perdi sete quilos. Só que é muito caro! (E3, 43 anos, IMC 37,66 kg/m²)

É importante atentar para a dimensão populacional da questão. Mulheres negras em condições de vida urbana, multíparas, com baixa escolaridade e renda têm, segundo Hoffmann (2012), maior probabilidade de apresentar obesidade. Independentemente da existência de predisposições genéticas, o rápido aumento da obesidade em populações geneticamente estáveis sugere a importância dos fatores socioambientais. (SWINBURN et al., 2015) Além da indústria e do comércio de alimentos, a tecnologia, o desenvolvimento urbano e sua interferência na vida cotidiana contribuem para a criação de ambientes obesogênicos, nos quais as mulheres de baixa renda configuram um grupo duplamente vulnerável. Ressalta-se, assim, a necessidade de debater as conexões entre cultura e excesso de peso e, particularmente, como o conceito de risco em sua configuração predominante, tende a reforçar estigmatização e culpa ao tratar problemas como a obesidade sob a égide da gestão individual.

\section{O DISCURSO DO RISCO, DA PROMOÇÃO DA SAÚDE E PRESCRIÇÕES DESCONTEXTUALIZADAS}

[...] Tão falando que o suco tá dando câncer [suco em pó]. Como éque eu vou fazer? Tem que ser da fruta então... Da fruta é melhor. Mas a fruta tá cara. Tem que ser do pozinho mesmo. (E12, 31 anos, IMC 32,2 kg/m²) 
O médico perguntou se eu tinha acesso à internet: 'ah você tem acesso a internet?'. Eu disse sim. Então tá bom... Ele disse: 'então abre lá e procura o que é diabetes, o que a diabetes faz'. E a gente vê... Eu tenho consciência de tudo, só que a gente pula certas partes. (E2, 47 anos, IMC $55,55 \mathrm{~kg} / \mathrm{m}^{2}$ )

A gestão de riscos é um dos eixos do discurso da promoção da saúde, que, por sua vez, enfatiza a autonomia dos sujeitos e dos grupos sociais como ponto de partida para uma reorientação estratégica em saúde. Os estudos de risco conferem cientificidade às recomendações que se disseminam em várias instâncias da vida social, exercendo poder de orientar, aconselhar e regular interferindo de forma intensa nas escolhas pessoais do cotidiano. (CZERESNIA, 2004) No caso do excesso de peso, uma série de controles e prescrições de autocuidado alimentares está ligada ao discurso do risco. (CASTIEL; FERREIRA; MORAES, 2014) Essas orientações envolvem, de modo geral, propostas de redução na ingestão de produtos densamente calóricos e aumento do consumo daqueles ricos em vitaminas, minerais e fibras. (KRAEMER et al., 2014)

A análise do risco epidemiológico apresenta uma lógica que isola fatores de exposição e avalia sua probabilidade de associação a agravos em saúde, buscando inferir a causalidade desses eventos. (AYRES, 2002) É importante destacar que a identificação de fatores de riscos contribuiu significativamente para o desenvolvimento da epidemiologia na conformação que a disciplina assumiu na confluência com outras formas de avaliação de risco por distintas áreas de conhecimento. Entretanto, o caráter analítico do conceito dificulta a contextualização dos processos epidemiológicos mais complexos tal qual o excesso de peso contemporâneo e, consequentemente, o estabelecimento de articulações mais amplas, fundamentais para sua compreensão. (CZERESNIA, 2004) Esse processo de redução, inerente à construção do modelo de análise do risco, acaba por se transportar à compreensão dos fenômenos estudados e isto é feito de uma forma que materializa modos de entender, construir tecnologias e administrar recursos para resolver os problemas de saúde.

O discurso profissional que orienta o autocuidado transmite preceitos, na maior parte dos casos, sem atentar para como estes podem 
ser adotados com efeito no cotidiano dos indivíduos. (OLIVEIRA et al., 2017) Associada aos limites econômicos, bem como a desejos ligados à própria cultura, evidencia-se uma dificuldade de adequação aos padrões dietéticos prescritos em dissociação com a realidade vivida, como nos aponta E10 (29 anos, IMC $30,89 \mathrm{~kg} / \mathrm{m}^{2}$ ), quando nos relata sua experiência de atendimento em saúde: "[...] na nutricionista, é sempre: não pode comer, não pode comer". Essas recomendações de autocuidado são quase sempre distanciadas da realidade cultural e financeira das entrevistadas, não se sustentando por muito tempo no cotidiano das mesmas. Nessa direção, é possível dizer que as orientações sob a regra do risco estão voltadas a uma lógica externa e defensiva, que dificulta a criação de alternativas afirmativas nos contextos reais. No caso do excesso de peso, principalmente da obesidade, resoluções restritivas realizadas sem uma sustentação que possibilite a efetivação de mudanças nas práticas alimentares podem acarretar sofrimento ao indivíduo.

Eu me pego comendo as coisas escondido... Assim... Comendo uma coisa assim [simula o corpo encolhido, olhando pros lados]. Gente, eu tô na minha casa! Por que é que eu tô comendo escondido? [...] Eu sinto que isso me atrapalhou muito! Eu só não sei como lidar com isso. (E15, 29 anos, IMC 57,7 kg/m²)

Acontece que intervenções prescritivas em geral deixam de considerar questões de caráter amplo como as condições de vida e de trabalho nas cidades e, particularmente, das formas de produção e distribuição alimentar que determinam efetivamente as opções de consumo possíveis nas periferias urbanas:

[...] com dieta, tem que comprar o filezinho todo dia, que é caro... As verduras, que tem que comprar todo dia, que tá muito caro; e assim, outras coisas mais. Arroz integral, pão integral... [...]. E assim, acaba que fica muito difícil, porque hoje você começa uma coisa, mas amanhã tu não tem mais dinheiro. Aí tu começa a furar... Fica cheio de buraco. E tu acaba abrindo mão. (E2, 47 anos, IMC $55,55 \mathrm{~kg} / \mathrm{m}^{2}$ )

É nesse contexto que a propagação de prescrições descontextualizadas da realidade das pessoas promove uma perda de referências 
alimentares, conforme indica Fischler (1979) ao trabalhar o conceito de gastro-anomia. Para ele, a grande quantidade de informações não só sobre o quê comer, mas como e quando fazê-lo disponíveis na atualidade promovem ansiedade e medo nas pessoas. Muitas vezes contraditórias, essas informações não esclarecem; pelo contrário, terminam por promover insegurança em relação às escolhas alimentares. É o caso das entrevistadas E4 (56 anos, IMC 30,82 kg/m²) e E6 (64 anos, IMC 29,77 $\left.\mathrm{kg} / \mathrm{m}^{2}\right)$, que mudaram a prática de comer arroz e feijão por compreenderem que esses alimentos "engordam".

Nessa direção, a lógica do risco exerce pressão sobre a carga de responsabilidade individual, associando-se a outros múltiplos discursos em relação à alimentação que mais confundem do que informam. As abordagens partem da perspectiva de que a posse de informações seria suficiente para a realização de boas escolhas alimentares, enfatizando-se a responsabilidade individual na gestão de hábitos e práticas. Entretanto, a posse de informação por si só não é suficiente para garantir um consumo alimentar seguro, nem torna mais fácil aderir a um determinado "estilo de vida".

A escolha do produto a ser consumido é de cada um, mas condicionantes mais amplos interferem na margem de liberdade das opções individuais, moldando possibilidades e induzindo comportamentos e hábitos. (CASTRO, 2015) Questões como prazer, convívio, tradições culturais, gosto, preço, praticidade e palatabilidade determinam o consumo alimentar de forma desigual. É necessário compreender mais amplamente as diferentes lógicas implicadas nessas escolhas, dentre as opções disponíveis.

A partir da idealização de um sujeito autônomo, capaz de estabelecer relações de custo/benefício em suas ações diárias, o discurso do risco culpabiliza aqueles que não conseguem se adequar. E13 (54 anos, IMC $66,83 \mathrm{~kg} / \mathrm{m}^{2}$ ) sente culpa e exemplifica com a orientação recebida de comer maçã quando tiver vontade de comer torresmo, sob a alegação de que o segundo alimento "faz mal” para sua saúde. Afirma não entender porque não estudou e, apesar de considerar não ter a "mente aberta pra certas coisas", E13 pensa muito sobre “o que comer” e argumenta que, se 
está com vontade de comer o torresmo, então vai comer porque, se não consegue emagrecer, não faz sentido não comer.

A racionalidade das escolhas efetivamente exercidas nem sempre corresponde às preconizadas pelos estudos de risco que orientam as práticas dos profissionais de saúde. Portanto, a margem da "livre escolha" se conforma de acordo com possibilidades e constrangimentos que se configuram em uma rede de processos mais amplos que se sobrepõe ao indivíduo. Essa mesma informante (E13), em diálogo com uma médica de Del Castilho, um bairro da Zona Norte do Rio de Janeiro, de quem ela gosta ("ela étão boa comigo"), se diz cansada e que às vezes percebe "uma confusão na minha cabeça e eu me perco... Aí eu choro, fico triste”.

Prescrições moralistas e normativas dificilmente dão lugar à compreensão dos significados que se ligam ao corpo e à própria alimentação, enquanto prática socialmente compartilhada, conectada à sociabilidade $\mathrm{e}$ prazer. Recomendações alimentares realizadas por profissionais se confundem com as veiculadas na mídia, estando associadas a um amplo mercado de consumo no qual uma série de programas e produtos "milagrosos" é comercializada com a promessa da conquista de uma boa forma. Destacam-se medicamentos anorexígenos ou disabsortivos, cirurgias, implantes, fórmulas, alimentos funcionais, shakes, dietas e programas especiais de atividade física.

A reflexividade presente no campo da nutrição se associa à polifonia dos discursos que se ligam à alimentação, tais quais o da saúde, da gastronomia e da beleza, amplificando a angústia da escolha e promovendo vulnerabilidade às estratégias de marketing que se vinculam à comercialização de produtos que supostamente são benéficos para a saúde. (PINTO et al., 2017) A narrativa de E15 expressa a maior exposição de determinados grupos ao consumo de serviços e atendimentos em saúde de procedência duvidosa:

Fui para num médico lá em Caxias, que está até preso [...]. Ai ele passou uma fórmula pra mim, cara à beça! Quase 200 reais. Eu tinha até visão com aquilo ali. [...] Não tinha fome, não comia... Depois, tinha um pozinho que botava embaixo da língua, aquilo me deixava leve... Mas tudo eu mandei fazer na farmácia de manipulação: tudo ótimo! [...] quando eu parei de tomar, engordei o dobro. (E15, 29 anos, IMC $57,7 \mathrm{~kg} / \mathrm{m}^{2}$ ) 
Santos (2008) coloca o quanto as preocupações com a alimentação e o corpo têm se colocado como uma questão central no cotidiano das pessoas. Em estudo realizado na cidade de Salvador, aponta-se a percepção de "corpo não saudável”, o "medo de morrer" e a preocupação estética alinhada às tentativas de mudanças entre seus entrevistados. A ideia do "cuidado de si", também presente entre os entrevistados de Santos (2008), reforça a ligação entre o discurso do risco e a culpabilização dos sujeitos. A crença de que a obesidade é uma condição autoinfligida nos permite estabelecer uma relação entre obesidade, estigma e risco. (GRACIA-ARNAIZ, 2010; PINTO; BOSI, 2010)

Os discursos de promoção da saúde, ao ressaltarem a responsabilidade individual na gestão de hábitos e comportamentos amparados no conceito de risco, além de terem pouca eficácia, colaboram com a formação e perpetuação desse problema de saúde alimentar em grande medida estigmatizante. (BREWIS, 2014; LINK; PHELAN, 2014) As informações sobre o risco acirram contradições, participando de um ciclo que retroalimenta o problema e incorpora o mercado de consumo para recursos tecnológicos e expertises, que se conformam reflexivamente a partir das necessidades criadas em meio ao avanço do conhecimento científico.

\section{CONSIDERAÇÕES FINAIS}

No presente trabalho, buscamos problematizar a relação entre excesso de peso e construção da identidade em mulheres de camadas populares em um contexto urbano específico na cidade do Rio de Janeiro. Partindo de uma compreensão de cidade como um lugar-espaço de realização de práticas de controle sobre o corpo, abordamos as conexões entre obesidade, risco e estigma como relacionadas ao caráter individualista das prescrições presentes nos discursos da promoção da saúde alimentar. As questões trazidas à tona pelas narrativas das entrevistadas evidenciam uma dupla vulnerabilidade das mulheres de camadas populares. Se, por um lado, as práticas alimentares desse grupo são conformadas por escassez de tempo e recursos materiais escassos, mas fomentado 
pelo exacerbado consumo alimentos industrializados, o discurso do risco presente no modelo de enfrentamento do sobrepeso/obesidade resulta em atribuição de culpa na medida em que desconsidera as questões macro e microssociais implicadas no fenômeno.

As narrativas das entrevistadas evidenciam uma ressignificação do habitus alimentar, que, por um lado, absorve discursos sobre o que seria uma alimentação saudável e, por outro, se realiza de acordo com disponibilidades concretas de vida. Os sentidos atribuídos ao corpo sofrem influência tanto pela disseminação midiática de um padrão de beleza idealizado, quanto pelo discurso do risco que associa o excesso de peso a agravos à saúde. Esse processo fomenta a estigmatização dessas mulheres em meio de dimensões sobrepostas: a gordura associada à aparência do corpo, a pobreza como expressão da classe e o gênero ligado ao feminino. Outra questão que se apresenta é a inviabilidade de consolidação das recomendações de saúde alimentar pautadas num modelo prescritivo, que não considera questões relacionadas às condições materiais de existência. Aspectos da vida individual, cultural, social, econômica e de mercado precisam ser pensados de modo integrado na abordagem do excesso de peso e obesidade.

A compreensão da interface território, risco epidemiológico e estigma ao se pensar o excesso de peso possibilita a elaboração de estratégias de intervenção mais pertinentes. Se, por um lado, abordagens individuais podem vir a ser exercidas de modo mais coerente com as condições materiais e existenciais das pessoas em contextos urbanos, por outro, a presença de ações de regulação da indústria devem ser incrementadas. No caso da obesidade, assim como de outros problemas com características equivalentes, a colaboração entre diferentes atores e áreas de conhecimento é uma condição essencial para construir alternativas criativas e vem de modo ainda tímido, sendo trilhada. Isso deve ser tentado mesmo considerando a força de grandes corporações que colaboram para que as contradições entre padrões de beleza e a realidade dos modos de vida concretamente possíveis acentuem cada vez mais a ocorrência de obesidade e estigma, retroalimentando determinadas demandas de consumo. 


\section{REFERÊNCIAS}

AGIER, M. Antropologia da cidade: lugares, situações, movimentos.

São Paulo: Editora Terceiro Nome, 2011.

AYRES, J. R. C. M. Epidemiologia, promoção da saúde e o paradoxo do risco. Revista Brasileira de Epidemiologia, São Paulo, v. 5, p. 28-42, 2002. Suplemento 1.

BOURDIEU, P. Sociologia. Organizado por Renato Ortiz. São Paulo: Ática, 1983.

BREWIS, A. A. Stigma and the perpetuation of obesity. Social Science \& Medicine, Amsterdã, v. 118, p. 152-158, Oct. 2014.

BREWIS, A. A.; HRUSCHKA, D. J.; WUTICH, A. Vulnerability to fat-stigma in women's everyday relationships. Social Science \& Medicine, Amsterdã, v. 73, n. 4, p. 491-497, Aug. 2011.

BRITO, F. O deslocamento da população brasileira para as metrópoles. Estudos Avançados, São Paulo, v. 20, n. 57, p. 221-236, maio/ago. 2006.

BURGOS, M. B. Cidade, territórios e cidadania. Dados: Revista de Ciências Sociais, Rio de Janeiro, v. 48, n. 1, p. 189-222, 2005.

BURGOS, M. B. Favela, cidade e cidadania em Rio das Pedras. In: BURGOS, M. B. (org.). A utopia da comunidade: Rio das Pedras, uma favela carioca. Rio de Janeiro: Editora PUC-Rio: Loyola, 2002.

CALVO, M. Migration et alimentation. Social Science Information, Thousand Oaks, v. 21, n. 3, p. 383-446, 1982.

CANELLA, D. S. et al. Ultra-processed food products and obesity in Brazilian households (2008-2009). PLoS One, São Francisco, v. 9, n. 3, p. e92752, 2014.

CANESQUI, A. M. Mudanças e permanências da prática alimentar cotidiana de famílias de trabalhadores. In: CANESQUI, A. M.; DIEZ GARCIA, R. W. (org.). Antropologia e nutrição: um diálogo possível? Rio de Janeiro: Fiocruz, 2005.

CANGUILHÉM, G. O normal e o patológico. 7. ed. Rio de Janeiro: Forense Universitária, 2012. 
CASTIEL, L. D.; FERREIRA, M. S.; MORAES, D. R. Os riscos e a promoção do autocontrole na saúde alimentar: moralismo, biopolítica e crítica parresiasta. Ciência \& Saúde Coletiva, Rio de Janeiro, v. 19, n. 5, p. 1523-1532, maio 2014.

CASTIEL, L. D.; MORAES, D. R.; PAULA, I. J. Terapeuticalização e os dilemas preemptivistas na esfera da saúde pública individualizada. Saúde e Sociedade, São Paulo, v. 25, n. 1, p. 96-107, 2016.

CASTRO, I. R. R. Desafios e perspectivas para a promoção da alimentação adequada e saudável no Brasil. Cadernos de Saúde Pública, Rio de Janeiro, v. 31, n. 1, p. 7-9, jan. 2015.

CASTRO, J. Geografia da fome: o dilema brasileiro: pão ou aço. 5. ed. Rio de Janeiro: Civilização Brasileira, 2005.

CUKIERMAN, H. L.; TEIXEIRA, M. O. Cotidianos de Manguinhos. Sociologias, Porto Alegre, ano 10, n. 19, p. 92-105, jan./jun. 2008.

CZERESNIA, D. Ciência, técnica e cultura: relações entre risco e práticas de saúde. Cadernos de Saúde Pública, Rio de Janeiro, v. 20, n. 2, p. 447-455, 2004.

CZERESNIA, D.; MACIEL, E. M. G. S.; MALAGÓN OVIEDO, R. A.

Os sentidos da saúde e da doença. Rio de Janeiro: Editora Fiocruz, 2013.

DA MATTA, R. Ofício do etnólogo ou como ter anthropological blues. In: NUNES, E. O. (org.). A aventura sociológica: objetividade, paixão, improviso e método na pesquisa social. Rio de Janeiro: Zahar, 1978.

DAMATTA, R. O que faz o Brasil, Brasil? Rio de Janeiro: Rocco, 1986.

DEVAUX, M.; SASSI, F. Social inequalities in obesity and overweight in 11 OECD countries. European Journal Public Health, Oxônia, v. 23, n. 3, p. 464-469, Jun. 2013.

DIEZ GARCIA, R. W. Reflexos da globalização na cultura alimentar: considerações sobre as mudanças na alimentação urbana. Revista de Nutrição, Campinas, v. 16, n. 4, p. 483-492, 2003.

DUARTE, L. F. D. Da vida nervosa: nas classes trabalhadoras urbanas. 2. ed. Rio de Janeiro: Zahar, 1988.

FERNANDES, T. M.; COSTA, R. G.-R. As comunidades de Manguinhos na história das favelas no Rio de Janeiro. Revista Tempo, Rio de Janeiro, v. 19, n. 34, p. 117-133, jan./jun. 2013. 
FISCHLER, C. Gastro-nomie et gastro-anomie. Communications, Paris, v. 31, n. 1, p. 189-210, 1979.

FISCHLER, C. Obeso benigno, obeso maligno. In: SANT'ANNA, D. Políticas do corpo. São Paulo: Estação liberdade, 1995.

FRASER, M. T. D.; GONDIM, S. M. G. Da fala do outro ao texto negociado: discussões sobre a entrevista na pesquisa qualitativa. Paidéia, Ribeirão Preto, v. 14, n. 28, p. 139-152, 2004.

GIDDENS, A. As consequências da modernidade. São Paulo: Editora UNESP, 1991.

GOLDENBERG, M. Gênero, "o corpo" e "imitação prestigiosa" na cultura brasileira. Saúde e Sociedade, São Paulo, v. 20, n. 3, p. 543-553, 2011.

GRACIA-ARNAIZ, M. Fat bodies and thin bodies: cultural, biomedical and market discourses on obesity. Appetite, Amsterdã, v. 55, n. 2, p. 219-225, 2010 .

HALL, S. A. Centralidade da cultura: notas sobre as revoluções culturais do nosso tempo. Educação e Realidade, Porto Alegre, v. 22, n. 2, p. 15-46, 1997.

HOFFMANN, R. Condicionantes do sobrepeso e da obesidade de adultos no Brasil, 2008-2009. Segurança Alimentar e Nutricional, Campinas, v. 19, n. 2, p. 1-16, 2012.

KRAEMER, F. B. et al. O discurso sobre a alimentação saudável como estratégia de biopoder. Physis: Revista de Saúde Coletiva, Rio de Janeiro, v. 24, n. 4, p. 1337-1360, 2014.

LINK, B. G.; PHELAN, J. Stigma power. Social Science \& Medicine, Amsterdã, v. 103, p. 24-32, Feb. 2014.

MACIEL, M. E. Cultura e alimentação ou o que têm a ver os macaquinhos de Koshima com Brillat-Savarin? Horizontes Antropológicos, Porto Alegre, v. 7, n. 16, p. 145-156, dez. 2001.

OLIVEIRA, T. C.; CZERESNIA, D.; VARGAS, E. P. "Eu tenho que me reeducar": discursos normativos e práticas alimentares relacionadas à perda de peso em mulheres de camadas populares. Demetra, Rio de Janeiro, v. 12 , n. 3, p. 523-538, 2017.

OLIVEIRA, T. C. et al. Concepções sobre práticas alimentares em mulheres de camadas populares no Rio de Janeiro, RJ, Brasil: transformações e ressignificações. Interface: Comunicação, Saúde, Educação, Botucatu, v. 22, n. 65 , p. 435-466, 2017. 
PARKER, R. Stigma, prejudice and discrimination in global public health. Cadernos de Saúde Pública, Rio de Janeiro, v. 28, n. 1, p. 164-169, jan. 2012.

PEIRANO, M. Etnografia não é método. Horizontes Antropológicos, Porto Alegre, v. 20, n. 42, p. 377-391, jul./dez. 2014.

PEIRANO, M. A favor da Etnografia. Rio de Janeiro: Relume-Dumará, 1995. PINTO, M. S.; BOSI, M. L. M. Muito mais do que pe(n)sam: percepções e experiências acerca da obesidade entre usuárias da rede pública de saúde de um município do Nordeste do Brasil. Physis: Revista de Saúde Coletiva, Rio de Janeiro, v. 20, n. 2, p. 443-457, 2010.

PINTO, V. R. A. et al. Influence of package and health-related claims on perception and sensory acceptability of snack bars. Food Research International, Amsterdã, v. 101, p. 103-113, Nov. 2017.

PUHL, R. M.; HEUER, C. A. Obesity stigma: important considerations for public health. American Journal of Public Health, Washington, DC, v. 100, n. 6, p. 1019-1028, Jun. 2010.

RODGERS, R. F. The role of the "Healthy Weight" discourse in body image and eating concerns: an extension of sociocultural theory. Eating Behaviors, Amsterdã, v. 22, p. 194-198, Aug. 2016.

SANTOS, L. A. O corpo, o comer e a comida: um estudo sobre as práticas corporais e alimentares na contemporaneidade. Salvador: Edufba, 2008.

STUCKLER, D.; NESTLE, M. Big food, food systems, and global health. Plos Med, São Francisco, v. 9, n. 6, p. e1001242, 2012.

SWINBURN, B. A. et al. Strengthening of accountability systems to create healthy food environments and reduce global obesity. Lancet, Londres, v. 385, n. 9986, p. 2534-2545, Jun. 2015.

SWINBURN, B. A. et al. The global obesity pandemic: shaped by global drivers and local environments. Lancet, Londres, v. 378, n. 9793, p. 804-814, Aug. 2011.

VARTANIAN, L. R.; SILVERSTEIN, K. M. Obesity as a status cue: perceved social status and the stereotypes of obese individuals. Journal of Applied Social Psychology, v. 43, n. S2, p. E319-E328, 2013.

VICTORA, C. G.; KNAUTH, D. R.; HASSEN, M. N. A. Pesquisa qualitativa em saúde: uma introdução ao tema. Porto Alegre: Tomo editorial, 2000. 
WORLD HEALTH ORGANIZATION - WHO. Expert Committee on Physical Status: the use and interpretation of anthropometry: report of a WHO expert committee. Genebra, 1995. (Technical Series, 854).

ZALUAR, A. A máquina e a revolta: as organizações populares e o significado da pobreza. 2. ed. São Paulo: Brasiliense, 1994. 